\title{
Duas Novelas do Decameron
}

\section{LuCIA STRAPPINI*}

RESUMO: A leitura aqui proposta do Decameron concentra-se especificamente em duas novelas: a primeira e a décima da quarta jornada (IV, 1 e IV, 10), que apresentam muitos pontos de interesse pela trama, pela caracterização dos personagens e pelos temas centrais da narrativa, fundada na conjunção e complementaridade de trágico e cômico como traços máximos e significantes da aventura humana sob todos os aspectos.

PALAVRAS-CHAVE: Decameron; paródia; trágico; cômico

ABSTRACT: La lettura del Decameron che propongo è concentrata specificamente su due novelle, la prima e la decima della quarta giornata (IV, 1 e IV, 10), che presentano molte ragioni di interesse nella trama, nella caratterizzazione dei personaggi e nei motivi di fondo della narrativa, fondata sulla congiunzione di tragico e di comico in quanto tratto massimamente significante della vicenda umana sotto tutti i profili.

PAROLE CHIAVE: Decameron; parodia; tragico; comico

\footnotetext{
* Università per gli Stranieri di Siena
} 
ABSTRACT: The proposed interpretation of The Decameron is specifically based on two stories, the first and the tenth day of the fourth story (IV 1 and IV, 10), presenting many points of interest to the plot, to create the characters and the central theme of the narrative, founded on the tragic and comic conjunction, as the most significant traces of the human adventure in all aspects.

KEYWORDS: Decameron; parody; tragic; comic 
_ leitura do Decameron que proponho concentra-se especificamente em duas novelas, a primeira e a décima da quarta jornada (IV, 1 e IV, 10), que apresentam muitas questões interessantes, como se verá, na trama, na caracterização dos personagens e nos motivos de fundo. Mas, antes de entramos nas análises pontuais, é oportuno considerar que se encontram concentrados aqui diversos pontos e temas que percorrem o livro inteiro. Naturalmente, esse aspecto não é verificável apenas neste caso; ao contrário, como se pode verificar em todas as grandes obras, os motivos condutores, ativos no tecido geral da obra, reverberam-se, de modo diverso, nas divisões parciais ou nos fragmentos textuais que se prestam a exames comparativos dos temas e dos motivos da obra em objeto, melhor e mais propriamente do que a leitura crítica de caráter panorâmico ou transversal. 
O nexo que liga em profundidade as duas novelas que proponho é representado pela paródia. A ideia, o conceito de paródia, estão presentes e ativos na literatura clássica e depois na cultura moderna em diversas acepções e funcionalidades. Seria necessário, por isso, redefinir o seu sentido e o seu uso para verificar a existência e a concreta, pontual operabilidade que, ao meu ver, assume um caráter diferente para cada contexto e em referência a cada obra. Limito-me aqui a utilizar a palavra e o seu conceito no sentido que será precisado a seguir.

Tem-se escrito muito sobre a atitude parodística do Boccaccio do Decameron, para afirmar a sua força ativa ou para negar a sua relevância na idealização compositiva e na estruturação narrativa. Parece-me que não está em discussão a atitude boccacciana, no Decameron, de conceber o inteiro universo representado (porque de universo se trata, na sua visão) sob o perfil da paródia. A começar mesmo pela Introdução, com a descrição da peste, que se dispõe precisamente entre citações, decalques, sugestões literárias relativas ao assunto e referências explícitas a uma veracidade dos eventos - "A mim mesmo desagrada ficar ruminando demoradamente tais misérias (...) conforme fiquei sabendo por pessoa digna de fé." (BOCCACCIO, 2013, p. 33, grifos meus) ${ }^{1}$ - convalidados pelo testemunho direto do narrador - "se tais coisas não tivessem sido vistas pelos olhos de muitos e também pelos meus, eu mal ousaria acreditar nelas, muito menos descrevê-las, por mais fidedigna que fosse a pessoa de quem as ouvisse." (2013, p. 28) -, que tentam, por um lado, reforçar o caráter realístico dos fatos narrados, mas, também, projetálos em uma dimensão outra que vai precisamente além daquele significado literal imediato que a asserção de veracidade reivindica. O sentido da citação, do decalque, vem, portanto, desse modo, invertido na direção oposta. Realismo (na peculiar acepção decameroniana) versus literariedade: um oposto a outro, um em função do outro.

É uma linha dupla, ambígua, pela qual se dispõe a matéria narrada, que encontra uma primeira e clara confirmação justamente na novela que abre as jornadas e a coletânea, aquela de ser Ciappelletto, conduzida coerentemente sob o fio da inversão. Em suma, creio que a paródia represente efetivamente uma chave de leitura relevante para compreender o sentido da obra, ou, ao menos, um dos sentidos, visto que seria uma operação certamente superficial querer reduzir a apenas uma unidade o conjunto das suas compreensões conceituais, literárias e culturais. Desse modo, mesmo tendo em mente essas advertências, pode-se ver com clareza como é amplamente operante no tecido do Decameron uma tensão paródica na reescrita de modelos, de fontes, de referências da mais ampla tradição literária (oral e escrita, italiana e europeia, clássica e moderna) e também na autoparódia, ou autocitação (bastaria pensar nos nomes dados

1 As fontes literárias, clássicas e medievais, foram pontualmente indicadas pela crítica decameroniana. Cfr. a edição de o Decameron, organizada por V. Branca (1987) Para essa versão, utilizaremos para os trechos de o Decameron a tradução feita por Ivone C. Benedetti. BOCCACCIO, Giovanni. Decameron. Rio Grande do Sul: L\&PM Editores, 2103. 
aos dez noveladores, alusivos também aos personagens das suas obras pré-decameronianas) ou reescrita dos próprios textos.

Na IV jornada do Decameron, como se nota, "fala-se sobre aqueles cujos amores tiveram fim infeliz." (2013, p. 235). Em plena sintonia com o tema, a novela que abre a jornada (IV, 1) é modulada com uma tonalidade trágica que eu definiria absoluta, ou seja, despojada de qualquer contrapeso irônico, cômico ou humorístico; e nessa linha se colocam as sucessivas novelas até a última que, como sempre, é atribuída a Dioneu, livre, por decisão comum, do vínculo temático, e cujas narrações orientam-se sempre pela maior liberdade em relação a qualquer obrigação, seja de conteúdo, seja de tonalidade narrativa.

Registra-se, nesse caso, um fenômeno singular: Dioneu conta, ao fim de uma jornada, uma novela que não só se distancia do tema comum, em virtude do seu "privilégio", mas que, no mais, se apresenta com toda evidência como uma versão cômica do acontecimento trágico de Tancredo e Guismunda encontrado na primeira novela, ou em outras palavras, uma inversão, uma anástrofe necessariamente intencional, dada a sua colocação (início e fim de jornada) e a oposição nítida das características dos dois respectivos narradores: Fiammetta, na 1, o personagem (desta obra e da outra, Elegia di Madonna Fiammetta, na qual Boccaccio tinha analisado as sutis manifestações da paixão amorosa) que mais do que os outros encarna o movimento passional, e Dioneu, na última jornada, personagem que desde o início se propõe como "mais que qualquer outro era encantado e cheio de argúcia." (2013, p. 38) e por isso livre no novelar, como se disse, do vínculo narrativo do tema da jornada. De resto, a tarefa de encerrar as jornadas e também toda a coletânea é reservada justamente a ele com as novelas de Gualtieri e Griselda (X, 10). Nessa última, como mostrei em outra ocasião (STRAPPINI, 2010), é invertido, nas considerações finais, cômicas e paródicas, até mesmo vulgares, o tom dominante do acontecimento narrado, em constante tensão no limiar da mais acentuada dramaticidade e melodramaticidade.

Voltando às duas novelas em confronto, podemos acrescentar outros elementos aos indícios da sua relação intencional e estruturada que intercorre entre elas, na direção da afinidade mútua ou do seu contrário. Uma primeira analogia se refere ao lugar de desenvolvimento da história (a cidade de Salerno / o principado de Salerno), lugar privado naturalmente de conotações históricas e geográficas determinadas e, portanto, projeção da imaginação fantástica. Ainda, ao príncipe de Salerno, Tancredo, corresponde o exímio cidadão, "grande médico" (2013, p. 285), Mazzeo della Montagna. Ambos homens ilustres, anciãos, socialmente dignos, os quais, 
porém, na dimensão privada, o primeiro nas vestes de pai, e o segundo nas de marido, encarnam plenamente o próprio papel de pais-donos, impondo às mulheres que são, por lei, submetidas aos seus absolutos desígnios. Tancredo, mesmo tendo que lidar com a filha que erarelacionando-se com "belíssima de corpo e rosto como nenhuma outra mulher jamais foi, e jovem, audaz e sensata mais do que porventura necessário a uma mulher." (2013, p. 242) e Mazzeo, igualmente ligado a uma "moça bonita e fidalga" (2013, p. 285), não querem ou não conseguem satisfazer as exigências naturais das duas mulheres. Guismunda rebaterá sobre seu pai, em um verdadeiro debate defensivo contra as acusações que ele lhe havia dirigido: "Portanto, tendo sido gerada por você, sou de carne e, tendo vivido tão pouco, ainda sou jovem; tanto por uma coisa quanto por outra, sou cheia de um desejo concupiscível (...)" (2013, p. 246). Da outra personagem, menos consciente e moralmente determinada, registra-se, de todo modo, o descontentamento: "motivo pelo qual ela vivia de péssimo humor". (2013, p. 285). Portanto, ambas as jovens tomam consciência da violência opressora à qual são submetidas no interior do ambiente familiar e ambas, em nome das legítimas exigências naturais, decidem encontrar o modo de satisfazer-se; as modalidades são, em muitos aspectos, diferentes, em conformidade com os seus respectivos status e inteligência individual e social. Guismunda, de fato

Assim, vivendo em meio ao luxo junto ao pai afetuoso, como grande dama que era, vendo que o pai, pelo amor que lhe tinha, pouco se preocupava em casá-la outra vez, e não lhe parecendo decoroso solicitá-lo, decidiu ter às escondidas, se possível, um amante valoroso. E, observando os muitos homens que frequentavam a corte do pai, fidalgo uns, outros não, tal como se vê nas cortes, e considerando as maneiras e os costumes de muitos, entre todos eles gostou mais de um jovem pajem do pai, cujo nome era Guiscardo, homem de nascimento bastante humilde, mas de virtudes e costumes nobres; vendo-o com frequência, começou a nutrir paixão secreta e ardente, louvando cada vez mais o seu modo de ser. (IV,1, 2013, pp. 242-3, grifos meus)

Enquanto a mulher do médico, "sensata e corajosa" (2013, p. 285)

decidiu sair à rua e esbanjar o alheio; e, depois de olhar vários e vários mancebos, acabou por se engraçar mais por um deles, em quem depositou 
todas as suas esperanças, todos os seus propósitos, toda a sua ventura. (IV, 10, 2013, pp. 285-6, grifos meus)

Existe um evidente nexo entre as duas ações-reações que consiste no caráter racional, meditado, reflexivo que sustenta as modalidades de satisfação do desejo. E, todavia, na cuidadosa procura do amante adequado, registra-se uma primeira marca do caráter distintivo da segunda novela, na direção da precisa inversão do modelo. Guismunda escolhe, de fato, um jovem da corte do pai, "homem de nascimento bastante humilde, mas de virtudes e costumes nobres" (2013, p. 243), preocupa-se em não causar um escândalo (“às escondidas” - 2013, p. 243), em não prejudicar a dignidade pública do pai-soberano. A mulher do médico, ao contrário, faz a sua escolha dispondo "sair à rua" (2013, p. 285) e ali encontra Ruggieri d'Aieroli, homem "nobre de nascimento, mas de vida viciosa" (2013, p. 286), ou seja, o exato contrário de Guiscardo².

Portanto, por um lado, as duas jovens tomam as próprias decisões submetendo-as ao pleno controle racional; distantes de qualquer impulsividade e concessões ao instinto, como também de rebeliões ou retaliações abertas, consideram, meditam, avaliam os elementos da sua situação e as modalidades de iniciativas que podem satisfazer o que lhes é indevidamente negado. Por outro, desse momento em diante as estradas das duas se distanciam radicalmente. Guismunda pagará com a vida esse sábio e virtuoso exercício, tendo governado sozinha e com plena responsabilidade moral o desenvolvimento dos eventos e as motivações das ações do pai-tirano, até o fatal desenlace, reivindicado como opção livremente assumida. Com isso mostrando (como outras protagonistas decameronianas) a superioridade de quem sabe, em qualquer circunstância, até mesmo extrema, domesticar a fortuna mediante a utilização da razão, do engenho, em resumo, da inteligência.

Trata-se de uma das marcas mais significativas da inspiração abertamente estoica que anima muitos personagens decameronianos, prontos conscientemente a sacrificar até a vida para afirmar, até as últimas consequências e a qualquer custo, a vontade de controle sobre cada fase da própria existência e, portanto, também da própria morte. O suicídio, por isso, nessa perspectiva, não é um ato de renúncia, mas ao contrário, de afirmação de si e da própria liberdade. Assim o entenderá, muitos séculos depois Leopardi, que a partir dessa ideia desenvolverá as páginas do Zibaldone e composições poéticas como Bruto minore e Ultimo canto di Saffo, entre outras. Naturalmente, a distância entre Boccaccio e Leopardi é grande em muitos aspectos; todavia, encontrá-los, nesse aspecto, seguindo a mesma linha de pensamento não é um dado marginal, tampouco casual,

2 Debrucei-me sobre esse aspecto no ensaio Tragico e comico in due novelle del Decameron (STRAPPINI, 2010), já citado. 
porque evoca a enorme influência que o estoicismo exerceu durante séculos na cultura europeia e italiana, em particular na versão realizada por Sêneca nas suas obras filosóficas e dramatúrgicas.

Ao engenho unido à virtude que anima o agir de Guismunda corresponde a condição de submissão ao domínio da fortuna (boccaccianamente entendida) que obriga a mulher do médico a recorrer à ajuda da astuta criada, a verdadeira artífice da feliz dissolução da intriga. A cadeia de acontecimentos tem início, em ambos os casos, de acidentes fortuitos (Tancredo adormecido no quarto da filha que assiste, sem ser visto, aos amores consumados com Guiscardo e, na outra novela, a sede que induz Ruggieri a beber o sonífero, dando início assim à intriga farsesca), mas desenvolve-se em dois percursos exatamente opostos: o primeiro, trágico e funesto em todas as passagens; o segundo, cômico e bizarro o segundo, com uma pontual correspondência invertida.

E, porém, em ambos os casos, ainda que tão diversos e distantes, a razão e o engenho das mulheres (mesmo envolvido de formas diferentes) prevalecem sobre a emotividade masculina, ligada ao exercício (inclusive brutal, no caso de Tancredo) do poder paterno e marital; esse dado, em última análise, consente às duas protagonistas dominar a história em todo o seu desenvolvimento, até o desfecho que sanciona para ambas o reconhecimento inclusive social de seu sucesso.

Assim doloroso foi o fim do amor de Guiscardo e Guismunda, como ouviram; e Tancredo, depois de muito chorar, tardiamente arrependido de sua crueldade, em meio à consternação geral de todos os salernitanos, ordenou que os dois fossem honrosamente sepultados no mesmo sepulcro. (IV,1, 2013, p. 249)

No fim, reconhecendo que Ruggieri era inocente, condenou os prestamistas que haviam roubado a arca a pagar dez onças e o soltou. Como Ruggieri achou bom isso, nem é preciso perguntar; e a mulher achou bom além da conta. Depois, com ele e com a estimada criada, que quisera lhe dar umas facadas, riram e festejaram várias vezes. $\mathrm{O}$ amor e o divertimento dos dois continuou cada vez melhor, e é o que eu gostaria que me acontecesse, mas não de ser posto numa arca. (IV, X, 2013, p. 291)

O feliz e jocoso final da IV, 10 apresenta-se com toda evidência como o exato oposto do trágico fim da IV, 1. Particularmente, as últimas palavras do narrador evocam, ainda outra vez por antítese, aquelas pronunciadas pelo rei da IV jornada, Filóstrato, no início da novela IV, 2, 
como comentário à precedente, um comentário completamente incomum porque definitivamente personalizado ${ }^{3}$ :

Minha vida pareceria valer pouco se houvesse de dá-la pela metade do prazer que Guismunda teve com Guiscardo, e a ninguém deve isso admirar, pois eu, vivendo, sinto mil mortes a cada hora, e por todas elas não me é dada nem uma única parcela de prazer. (IV, 2, 2013, p. 250)

Pode-se notar um elemento ulterior de comparação na função operativa realizada pela bebida, mortal, no caso de Guismunda, que beberá voluntariamente o veneno colocado na taça de ouro que continha o coração de Guiscardo (arrancado do amante assassinado por ordem do pai) e, no caso de Ruggieri, pela bebida com o sonífero preparada pelo médico para um paciente seu e inadvertidamente bebida por Ruggieri, fato que dá origem a todo a intriga que o conduziria à condenação e à morte se não fosse salvo pela sagacidade da mulher. $\mathrm{O}$ motivo dramático do coração ingerido, retomado por Boccaccio de uma reconhecida tradição medieval ${ }^{4}$, é ulteriormente enobrecido pela magnânima determinação de Guismunda:

Dito isso, pediu que lhe dessem a jarrinha na qual estava a água que preparara no dia anterior; colocou a água na taça onde estava o coração lavado por muitas lágrimas e, sem nenhum temor, levou-a aos lábios e bebeu tudo; depois de beber, com a taça na mão foi para o leito e, nele acomodando o corpo da maneira mais decorosa ${ }^{5}$ que conseguiu, ao seu coração encostou o do amante morto e, sem dizer nada, ficou à espera da morte. (IV, 1, 2013, p. 249)

Permanece, na IV, 10, a água alterada (aqui, no caso, não com o veneno, mas com o sonífero), porém a severa resolução se torna infortúnio acidental e, à gravidade de Guismunda distendida "honestamente" (“decorosamente") sobre a cama à espera silenciosa da morte, corresponde ao momento em que o jovem adormecido pelo sonífero cai no chão, como "un corpo morto"6

Estava, pois, Ruggieri no quarto a esperar a mulher quando, ou por canseira do dia, ou por ter comido algo salgado, ou talvez por costume, sentiu uma sede imensa

3 Cfr. Mariella Di Maio, Il cuore mangiato. Storia di un tema letterario dal Medioevo all'Ottocento, Guerini e associati, Milano, 1996.

4 O texto original de Boccaccio usa o termo "onesto" que encerra os vários significados da virturde, contudo a tradutora optou pelo termo decoroso, provavelmente por acreditá-lo mais abrangente (N.T.).

5 Citação completa da passagem: "Ruggieri, com o empurrão, caiu de uma arca sobre a qual estava, sem dar mais sinal de vida do que se estivesse morto". (2013, p. 287 - N.T.)

6 Remeto, inclusive nesse ponto, ao meu artigo já citado, Tragico e comico in due novelle del Decameron (STRAPPINI, 2010). 
e acabou vendo na janela aquela jarrinha de água que o médico tinha preparado para o doente; achando que era água de beber, levou-a à boca e tomou tudo; não demorou muito para sentir um tremendo sono e adormecer. (2013, p. 286)

e o susto da mulher do médico, a perturbação e o apelo a uma saída fortuita

Mas, depois de um tempinho, com medo de somar desonra àquela perda, considerou que era preciso encontrar, sem nenhuma demora, um modo de tirá-lo de casa, morto daquele jeito; e, não sabendo o que fazer para tanto, chamou baixinho a criada e, mostrando-lhe sua desventura, pediu conselho. (IV, 10, 2013, p. 287)

Para entender pontualmente todo o jogo entrecruzado de citações, seria necessário ler em paralelo as duas novelas, integralmente. Aqui, terá sido suficiente indicar, nessa direção, alguns traços salientes que nos permitem verificar como o percurso narrativo das duas novelas é modulado em sequências análogas, e, sobretudo, que a inversão do trágico da primeira no cômico da segunda constitui o sentido essencial do nexo entre as duas narrações e as suas conclusões, confirmando a modalidade de representação e de narração tipicamente boccacciana que se funda sobre a conjugação/complementariedade do trágico e do cômico enquanto traço maximamente significante do acontecimento humano sob todos os aspectos ${ }^{7}$.

Sem dúvidas, também no grande modelo dantesco da Comédia, os dois tons são igualmente presentes e ativos. No Decameron, essa visão é colocada precisamente a serviço do retrato do mundo terreno, todo o mundo terreno, nas suas diversas manifestações. Por isso, não apenas, como na Comédia, a escrita modula-se sob a tonalidade do trágico ao lado ou, às vezes, junto à tonalidade do cômico, de modo que ambas são valorizadas ao máximo; mas, mais do que isso, diverte-se ${ }^{8}$. propondo a versão cômica do acontecimento trágico (e vice-versa) com a ambição, por sua vez, bem sucedida, de reproduzir na narração, na literatura, a infinita variedade das existências humanas.

Tradução Larissa Cabrini Morgato e Thiago Basile

7 São muitas as análises e as reflexões dos estudiosos sobre o prazer de narrar como pilar central da inspiração boccacciana e da sua ideia de civilização e da eficácia do viver. É considerada exemplar, nesse sentido, a novela IV, 1 (Madonna Oretta), mas, com efeito, esse fio atravessa proficuamente a inteira obra que poderia ser relida sob esse prevalecente perfil. 


\section{Referências Bibliográficas}

BOCCACCIO, G. Decameron. A cura di Vittore Branca. Torino: Einaudi, 1987.

DI MAIO, M. Il cuore mangiato. Storia di un tema letterario dal Medioevo all'Ottocento. Milano: Guerini, 1996.

STRAPPINI, L. Tragico e comico in due novelle del Decameron. In Revista de Italianística, n. XIXXX, 2010, p. 17-29.VELLI, G. Memoria. In BRAGANTINI, R.; FORNI, P. M. (a cura di). Lessico critico decameroniano. Torino: Bollati Boringhieri, 1995. p. 222-248.

VELLI, G. Seneca nel Decameron. In Petrarca e Boccaccio. Tradizione, memoria, scrittura.

Padova: Antenore, 1991. p. 209-221 